\title{
Sobre el origen de la Bacteriología Experimental en Chile
}

\section{The history of microbiology in Chile: About the origin of experimental bacteriology}

The origin of Bacteriology in Chile is intimately bound to the life of the physicians Vicente Izquierdo Sanfuentes and Francisco Puelma Tupper. Both were awarded in 1874 with a government fellowship to study in the most prestigious universities of Europe. Dr. Izquierdo studied Histology and Dr. Puelma Tupper Pathology. After their return to Chile in 1879, both founded in the Faculty of Medicine of the University of Chile, the first experimental laboratories in their respective disciplines. It was in those laboratories that the new science of microbiology started to be developed slowly. This discipline was just consolidating itself in Europe, led by the famous scientists Louis Pasteur and Robert Koch.

(Rev Med Chile 2010; 138: 913-919).

Key words: Bacteriology; Chile; History of Medicine.

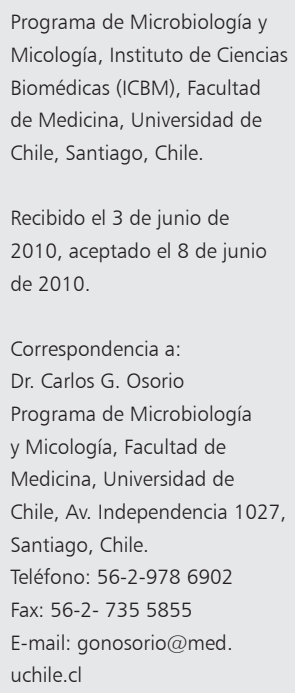

\section{La enseñanza de la higiene}

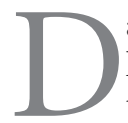
aremos primeramente una breve reseña de la enseñanza de la Higiene en nuestro país, por estar esta disciplina estrechamente ligada al origen de la enseñanza de la Bacteriología. El estudio de la Higiene comienza formalmente con el primer Curso de Medicina de 1833. El primer profesor de Anatomía de la nueva Escuela, Dr. Pedro Morán (1833-1841), según el plan de estudios de este primer curso, debía además enseñar durante el segundo año de la carrera los ramos de Fisiología e Higiene. El enfoque y textos utilizados por el Dr. Morán y su inmediato sucesor, el Dr. Francisco Julio Lafargue, profesor de Anatomía y Fisiología entre 1841-1846 (no se tiene claridad de si realmente enseñó la Higiene), para la enseñanza de este ramo, nos son desconocidos. Es importante destacar aquí que, a pesar de que la disciplina de la Higiene aparece nombrada en los planes de estudios de 1833 y 1845 asociada a la Fisiología en el segundo y tercer año, respectivamente, no tenemos la certeza documental de que efectivamente se haya enseñado. El tercer profesor de Anatomía, Fisio- logía e Higiene, Vicente Antonio Padín del Valle (profesor entre 1847-1868), sí enseñó la Higiene, pues según los Anales de la Universidad de 1852 sus clases se basaban en el Compendio de Higiene Pública y Privada publicado originalmente por Leopold Deslandes en $1827^{1}$.

El Dr. Padín enseñó Anatomía hasta 1861 ,siendo sucedido en este ramo por el Dr. José Joaquín Aguirre Campos, continuando con la enseñanza de la Fisiología y Medicina Legal hasta su muerte en 1868. Las fuentes son nuevamente oscuras respecto a lo ocurrido con la enseñanza de Higiene. Por otra parte, en el programa de estudios de 1860 la enseñanza de la Higiene se trasladó a $5^{\circ}$ año, paralelamente al ramo de Clínica Interna o Médica. A falta de mayor evidencia documental, planteamos que el profesor de Clínica Interna del período 1861-1869, Dr. Jorge Hércules Petit habría dirigido este ramo. Tenemos evidencia que el Dr. Ramón Elguero del Campo, Profesor de Patología Interna, dirigió esta clase entre 1869-1871. Entre 1871-1883, el Dr. Francisco Javier Tocornal Grez (Decano de la Facultad de Medicina entre 18511855), enseñó esta disciplina paralelamente a la 
Cátedra de Pediatría. Su enseñanza era meramente teórica y se basaba, al parecer, en la obra del francés Auguste Tessereau de 1855, titulada Cours D'Hygiène, traducida por él al castellano (Curso Elemental de Higiene, 1872). Lo sucedió luego el Dr. Federico Puga Borne, quien dirigió paralelamente la Cátedra de Medicina Legal entre los años 1884-1896 2 .

\section{Teoría miasmática de las enfermedades infecciosas}

Existen algunos trabajos publicados entre 1843-1880 en los Anales de la Universidad de Chile y Revista Médica de Chile que demuestran que el tema de las enfermedades infecciosas y epidémicas era considerado de especial relevancia para el cuerpo médico nacional. La mayoría de estos trabajos consideraba que la causa de estas enfermedades era multifactorial, asignando un rol relevante en su génesis a factores del hospedero (edad, estado nutricional, etc) y ambientales (ozono, virus, efluvios miasmáticos, etc). Entre los trabajos más característicos citaremos la memoria de Licenciado del Dr. Rafael Wormald de 1850 que versa sobre la gangrena de los hospitales ${ }^{6}$. En este trabajo cuando se habla sobre sus causas se expresa: "Todas estas circunstancias son mui adecuadas para producir la corrupción del aire en que se hallan los heridos i alterada la atmósfera de este modo por las exhalaciones concentradas de tantos hombres $i$ por los vapores que emanan de las úlceras $i$ heridas así como de sus deposiciones albinas, engendra en las soluciones de continuidad esta desjeneración pútrida...". En otro párrafo se dice: "Es sobre todo temible la infección miasmática del aire cuando los heridos están ya enfermos de antemano,...”. En el trabajo del Dr. Francisco Javier Tocornal sobre el origen miasmático de las fiebres intermitentes de 1857, se menciona: "Las causas que dan lugar a estas exhalaciones, son las aguas estagnantes, las aguas subterráneas, las elaboraciones que suceden en el interior del suelo, sobre todo cuando este es poroso, volcánico, único, descomponible, abundante en materias orgánicas i en sulfatos" "Tremendamente interesante es el discurso de incorporación a la Facultad de Medicina del Dr. Valentín Saldías en 1865 sobre la causa de las epidemias ${ }^{8}$. La siguiente cita corresponde a este trabajo: "Se ha hablado de miasmas, de infección por los mismos afectados, de transmisión de un virus, lo que ha dado lugar a la doctrina del contajio que cuenta con muchos sostenedores; del ozono, producción de parásitos i hasta influencias siderales, sin que ninguna de estas causas haya podido comprobar sus efectos de un modo preciso, indudable; ninguna de ellas sostiene su carácter; lo que hoy parece debido a un miasma, otro día es al contagio, otro al ozono". La memoria de Licenciado del Dr. Ramón Allende Padín (abuelo del Presidente Salvador Allende Gossens): Observaciones sobre el tifo, conocido en Chile vulgarmente con el nombre de Chavalongo de $1865^{9}$. Este último trabajo, cuando se refiere a la etiología del tifus exantemático (tifo), expresa textualmente: "En verdad, siempre se ocultarán a nuestra vista esos fenómenos intimos que quisiéramos conocer, quedemos satisfechos con saber que existen. No pretendamos sorprender los arcanos de la ciencia; nuestra marcha en tales investigaciones sería vacilante, i de hipótesis en hipótesis hallaríamos al fin, sino el error, la duda". Finalmente mencionaremos las memorias para optar al grado de Licenciado del Dr. Pablo Zorrilla (sobre la fiebre puerperal de 1862) y del Dr. Adolfo Murillo (enfermedades del hígado en Chile de 1862), que presentan una visión similar ${ }^{10,11}$. Estos trabajos demuestran claramente que en el cuerpo médico de la época no existía una idea clara y homogénea sobre la causa de las enfermedades infecciosas. Se aceptaba por algunos que la etiología era multifactorial, por otros, que faltaban aún argumentos convincentes que demostrasen una u otra teoría y aún por otros, que tal vez nunca se pudiese conocer verdaderamente la causa última de estos fenómenos. Salvo por algunas notables excepciones ${ }^{12}$, se desconocían casi totalmente los revolucionarios cambios que estaban ocurriendo en ese momento en Europa respecto de la teoría de los gérmenes liderada por Louis Pasteur.

\section{Maestros precursores formados en Europa}

La aceptación de la nueva teoría de los gérmenes sólo vendría a producirse, no sin encontrar una enconada resistencia, por un hito fundamental en la historia de la medicina y ciencias biológicas nacionales: el envío en 1874-1875 de los cinco primeros becados chilenos a Europa por el Dr. José Joaquín Aguirre (Decano de la Facultad de Medicina entre 1867-1875 y luego entre 1884-1889). 
Los jóvenes elegidos por el destino para cambiar los rumbos de la medicina nacional fueron los doctores Francisco Puelma Tupper (Anatomía Patológica), Manuel Barros Borgoño (Cirugía), Vicente Izquierdo Sanfuentes (Histología), Carlos Sazié Heredia (Enfermedades Mentales) y Máximo Cienfuegos Sánchez (Oftalmología). Es importante recordar que en esos años la Escuela de Medicina estaba localizada y funcionaba en un antiguo edificio ubicado en la calle San Francisco e inaugurado en 1863 (adyacente y al sur del antiguo Hospital San Juan de Dios) ${ }^{13}$.

\section{Vicente Izquierdo Sanfuentes (1850-1926)}

El Dr. Izquierdo nace en Santiago en 1850. Cursó sus primeros estudios en el Instituto Nacional y posteriormente para complacer a sus padres ingresó a la Universidad de Chile a estudiar Leyes. Después de conseguir su título en Derecho a fines

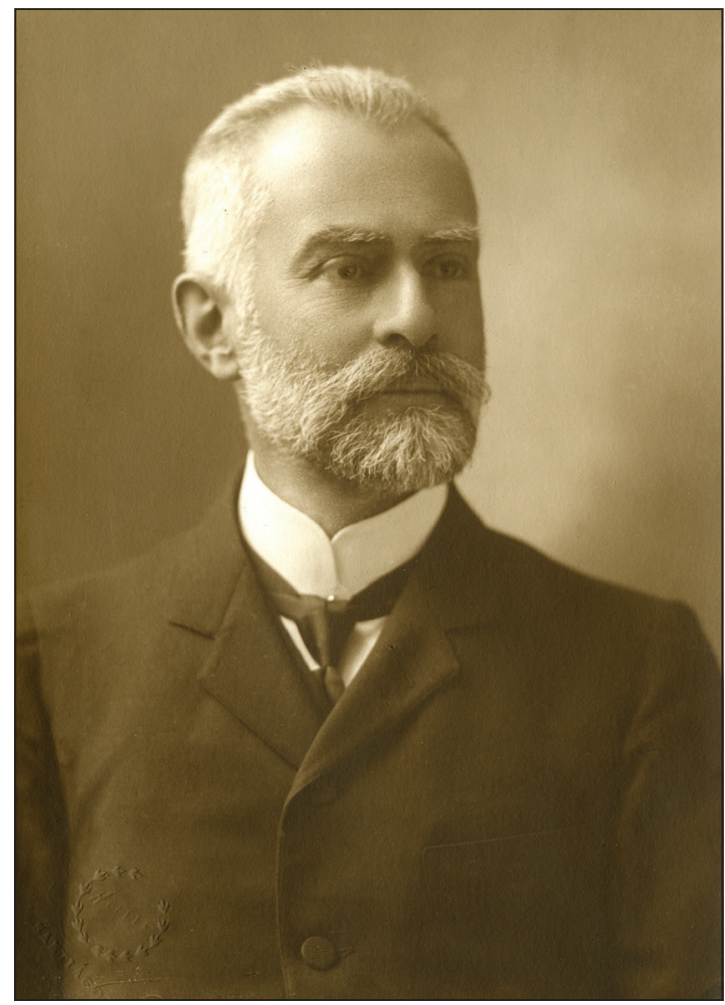

Figura 1. Dr. Vicente Izquierdo Sanfuentes (1850-1926). Primer Profesor Titular de la Cátedra de Histología de la Facultad de Medicina de la Universidad de Chile. Colección Museo Nacional de Medicina, Facultad de Medicina, Universidad de Chile. de 1872, ingresó a estudiar Medicina, recibiendo su Licenciatura el 5 de marzo de 1875. Ya en abril de 1875 estaba embarcándose con destino a Europa. Tras cinco años de prolíficos estudios en Alemania, junto a los célebres morfólogos alemanes Wilhelm Hiss (1831-1904) en Leipzig y Wilhelm Waldeyer (1836-1921) en Estrasburgo, retorna al país. Su regreso coincide con el inicio de la Guerra del Pacífico y decididamente, junto a sus compañeros Manuel Barros Borgoño, Francisco Puelma Tupper y Máximo Cienfuegos, establecen el Hospital de Sangre Domingo Matte en calle Lira, entre Santa Victoria y Santa Isabel. Este hospital provisorio tuvo el honor de ser el primer establecimiento del país donde se aplicó la cirugía antiséptica creada por Joseph Lister en Inglaterra. El Dr. Izquierdo fue luego nombrado Profesor de Histología en 1882 y con muy escasos recursos se dedicó a formar su Laboratorio de Histología. Este Laboratorio se ubicaba, aunque carecemos de datos exactos, en la Sección Universitaria del Instituto Nacional ${ }^{5}$. En sus primeros años en la Cátedra de Histología, el Dr. Izquierdo publicó algunos trabajos en el área de la Bacteriología. Así en el año 1884, aparece su primer trabajo de Bacteriología Experimental respecto a Mycobacterium tuberculosis o bacilo de Koch en Chile, tan sólo un año después de su descubrimiento por Roberto Koch ${ }^{14}$. Además publicó un trabajo sobre el patógeno venéreo Neisseria gonorrhoeae, descrito por primera vez por el microbiólogo alemán Albert Neisser en $1879^{15}$. El Dr. Izquierdo, desarrolló posteriormente una destacadísima labor científica, publicando numerosos e importantes trabajos en el área de la histología normal y patológica ${ }^{16}$. Participó además con entusiasmo en labores docentes y clínicas, formando generaciones de médicos ilustres por un período de casi cuatro décadas ${ }^{16}$.

\section{Dr. Francisco Puelma Tupper (1850-1933)}

El doctor Puelma Tupper nació en Santiago en 1850. Estudió en el Instituto Nacional y en el año 1872, ya como alumno de Medicina, la Municipalidad de Santiago le otorgó una medalla de oro por su encomiable labor médica durante una gran epidemia de viruela que diezmaba a la capital (recordemos que a causa de esta misma epidemia el gobierno de la época decidió construir los Hospitales San Vicente de Paul y El Salvador ${ }^{17}$. El 11 de enero de 1874 se embarca a Europa para especializarse en el área de la Anatomía Patológica, 
estudiando en las prestigiosas Universidades de Estrasburgo, Viena y Berlín (en Berlín recibió lecciones, entre otros, del afamado patólogo alemán Rudolf Virchow). A su retorno a Chile en 1879, al iniciarse la Guerra del Pacífico, participó como médico del Hospital de Sangre Domingo Matte en Santiago, junto a sus amigos Dres. Izquierdo y Barros Borgoño (ver detalles en sección anterior). El Dr. Puelma Tupper fue nombrado Profesor Titular de la Cátedra de Anatomía Patológica en 1883 y sin perder tiempo, fundó un Laboratorio de Anatomía-Patológica (ubicado en la Sección Universitaria o en el Hospital San Juan de Dios, los datos son contradictorios) $)^{5}$. En este laboratorio, que disponía de microscopios modernos y preparaciones microbiológicas traídas desde Europa, realizó destacados estudios experimentales en el área de la Bacteriología junto a su alumno y ayudante Dr. Alejandro del Río Soto Aguilar ${ }^{18,19}$. Es interesante rememorar las palabras del Dr. Tupper respecto a la resistencia que encontró en la capital el método antiséptico importado por ellos desde Europa: "costó convencer a la gente de la existencia de los microbios, como no los veían y nosotros los jóvenes los veíamos en todas partes; nos creían per-

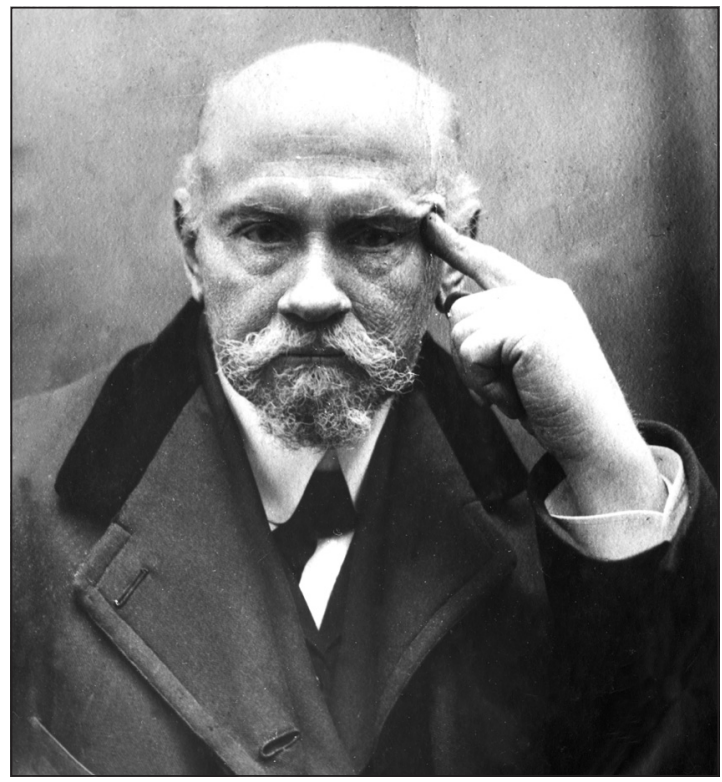

Figura 2. Dr. Francisco Puelma Tupper (1850-1933). Primer Profesor Titular de la Cátedra de Anatomía Patología de la Facultad de Medicina de la Universidad de Chile. Colección Museo Nacional de Medicina, Facultad de Medicina, Universidad de Chile. turbados, alucinados; en 1879 me caricaturizaron matando con una escopeta, microbios a diestra $y$ siniestra"20,21.

\section{Ayudantes y alumnos aventajados}

\section{Dr. Aureliano Oyarzún Navarro (1858-1947)}

El Dr. Oyarzún nació en la isla de Dalcahue en Chiloé en 1858. Se tituló en 1885 con su memoria titulada "Elefantiasis del Escroto". En enero de 1887 arribó al país una epidemia de Cólera que se extendió hasta julio de 1888. Durante esta epidemia el Dr. Oyazún tuvo un importante desempeño, realizando un extenso y detallado informe anátomopatológico sobre algunos pacientes fallecidos, en su calidad de Director del Lazareto de Coléricos de Santa María de la provincia de Aconcagua. Para ello utilizó un microscopio de Zeiss con condensador de luz de Abbé, preparaciones microbiológicas enviadas desde el laboratorio de Koch en Berlín, cultivos sólidos en gelatina peptonizada de Koch, que trasladó personalmente para la ocasión desde el Laboratorio del Dr. Puelma Tupper en la Universidad $^{22}$. En dicho informe se expresa: "Decidí entonces abrir la línea blanca de un individuo re-

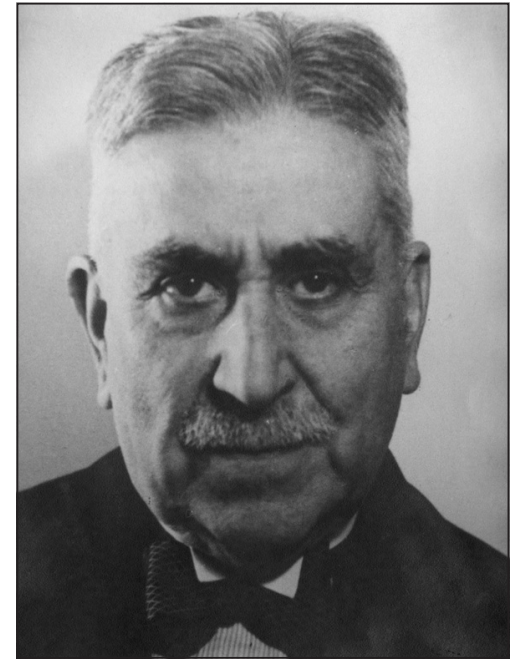

Figura 3. Dr. Aureliano Oyarzún Navarro (1858-1947). Segundo Profesor Titular de la Cátedra de Anatomía Patología de la Facultad de Medicina de la Universidad de Chile. Colección Museo Nacional de Medicina, Facultad de Medicina, Universidad de Chile. 
cién muerto en el período áljido de la enfermedad, estraer un asa del íleon i examinar los copos mucosos que ella contuviera; por este medio obtuve siempre una sola especie de bacilos, que sin duda eran los descritos por Koch en el cólera asiático. Seguí mis investigaciones en este sentido i poco tiempo después pude enviar a US, las seis preparaciones histológicas que hizo examinar por el profesor de anatomía patolójica de la Universidad i que resultaron contener efectivamente el Bacillus comma". Recordemos que el Bacillus comma no es otro que la bacteria hoy denominada Vibrio cholerae.

En premio a su actuación, el supremo Gobierno lo envió a Europa a especializarse en Anatomía Patológica e Higiene entre 1888-1891 (allí realizó estudios junto a los famosos patólogos alemanes Rudolf Virchow y Carl Weigert). Luego de retornar a Chile, fundó en 1892 el Pabellón o Sección de Microscopía-Bacteriología del Instituto de Higiene, dirigiendo además la construcción del primer Desinfectorio Público del país. El Dr. Oyarzún tuvo posteriormente una destacada trayectoria en el campo de la antropología, con destacados trabajos sobre las poblaciones prehispánicas de Chile ${ }^{23}$.

\section{Dr. Alejandro del Río Soto Aguilar (1867-1939)}

El Dr. Alejandro del Río, hermano del destacado pediatra Dr. Roberto del Río, nació en Santiago en 1867. Lo encontramos recibiendo el grado de Bachiller en la Facultad de Medicina en 1887 (junto al Dr. Mamerto Cádiz) y suponemos, por tanto, que se titularon juntos en 1889. Recordemos que antes de titularse había sido ayudante del Dr. Puelma Tupper en su laboratorio de Anatomía Patológica, donde había publicado interesantes trabajos. Destacaremos un interesante fragmento de su trabajo titulado "El microorganismo de la disentería" de 1888 (Shigella, el bacilo de la disentería, fue descubierto por Kiyoshi Shiga en $1887)^{18}$. Respecto al examen de deposiciones de una paciente, se describe lo siguiente:

"Preparaciones por desecación teñidas por fuchsina dejan ver micro-organismos que pueden referirse a las siguientes formas:

1. Bacilos. Hay dos especies: unos largos, rectos ó encorvados que nada de particular presentan, y otros más pequeños, curvos, semejantes en algo al Bacillus-komma, pero que un examen atento permite diferenciarlos.

2. Micrococcus. Se encuentran en escaso número, aislados ó reunidos en grupos de dos ó tres.
3. Micro-organismos de forma especial que con débiles aumentos parecen á primera vista diplococcus, pero que una observación cuidadosa y aumentos poderosos dejan ver claramente que se trata de bacilos acinturados ó estrangulados en su centro y con las extremidades ligeramente redondeadas". Luego de aislar colonias en tubos con medio sólido preparado en base a gelatina o agar-agar, realiza su descripción microscópica: "Preparaciones de las colonias núm. I, muestran estar compuestas exclusivamente de los bacilos acinturados ya mencionados".

El Gobierno chileno de la época decide enviar al Dr. Alejandro del Río a Alemania en 1892 para especializarse en la nueva ciencia de la Bacteriología. El Dr. del Río tiene el honor de haber sido el primer Profesor de la Cátedra de Bacteriología creada en la Facultad de Medicina de la Universidad de Chile en $1895^{24}$.

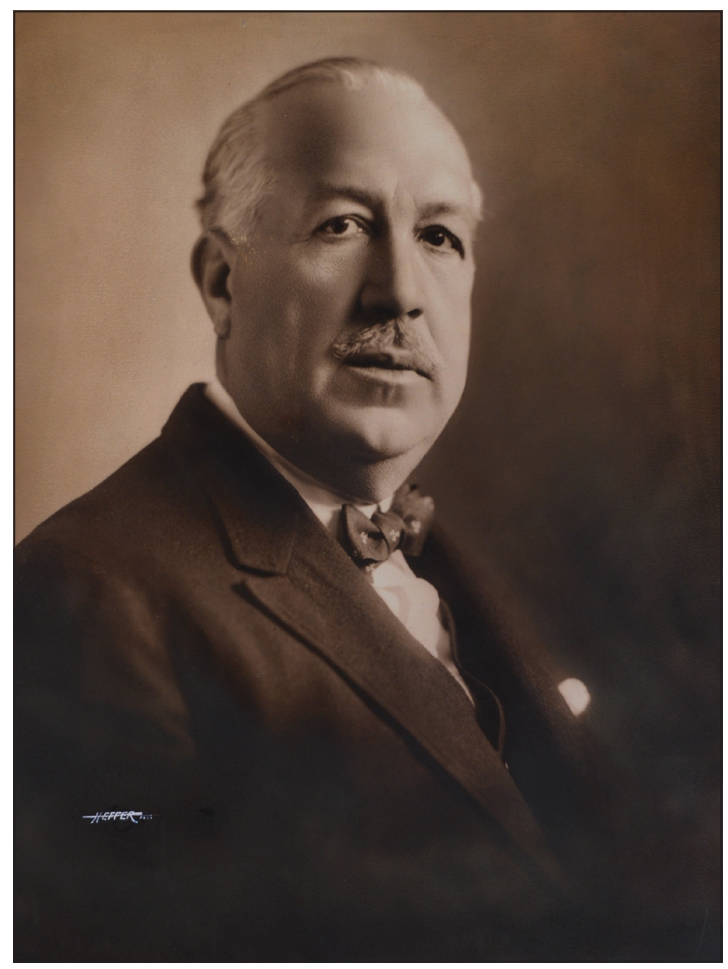

Figura 4. Dr. Alejandro del Río Soto Aguilar (1867-1939). Primer Profesor Titular de la Cátedra de Bacteriología e Inmunología de la Facultad de Medicina de la Universidad de Chile. Período 1896-1901. Colección Museo Nacional de Medicina, Facultad de Medicina, Universidad de Chile. 


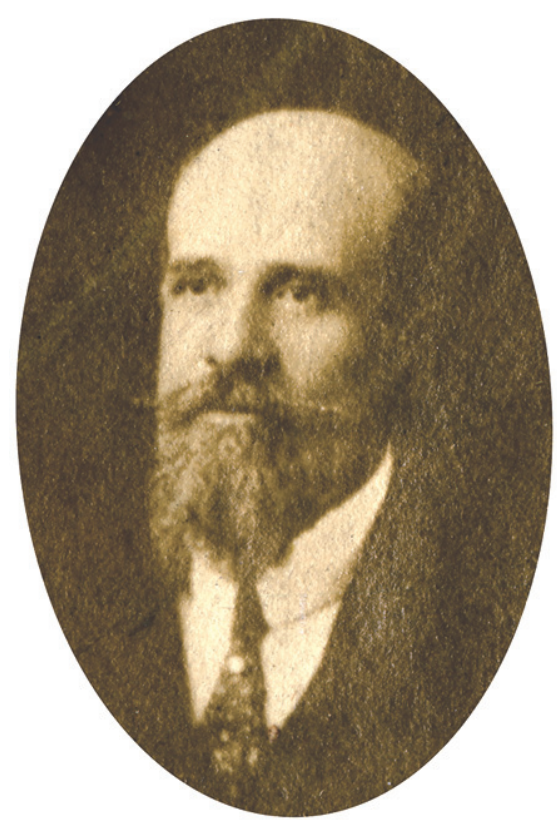

Figura 5. Dr. Mamerto Cádiz Calvo (1863-1929). Segundo Profesor Titular de la Cátedra de Bacteriología e Inmunología de la Facultad de Medicina de la Universidad de Chile. Período 1901-1928. Colección Museo Nacional de Medicina, Facultad de Medicina, Universidad de Chile.

\section{Dr. Mamerto Cádiz Calvo (1863-1929)}

El Dr. Cádiz nació en Santiago en 1863. No disponemos de la información exacta, pero podemos inferir con seguridad que sus maestros de Histología y Anatomía Patológica en la Facultad de Medicina fueron, respectivamente, los Dres. Izquierdo y Puelma Tupper. Sabemos que para la epidemia de Cólera de 1887, el Dr. Cádiz trabajó como ayudante del Dr. Cornelio Guzmán en el Lazareto del Poniente o de Matucana en Santiago, siendo esta una experiencia determinante para desarrollar su interés por esta nueva ciencia. Luego de un breve período como médico en Rengo (recordemos que se tituló en 1889 con su memoria “Tratamiento Quirúrgico de las Hernias”), regresó a Santiago ingresando a la sección de MicroscopíaBacteriología del Instituto de Higiene que dirigía el Dr. Aureliano Oyarzún, a quien reemplazó en el cargo al cabo de unos meses. Posteriormente fue nombrado Jefe de la Sección de Seroterapia en 1896. El profesor Cádiz fue entonces becado por el Gobierno a Europa entre 1897-1899, trabajando en el Instituto Pasteur e Instituto Koch de Berlín. El
Dr. Cádiz tiene el mérito de haber sido el maestro que consolidó la enseñanza de la Bacteriología en Chile, siendo el inmediato sucesor del Dr. Alejandro del Río en la Cátedra de Bacteriología e Higiene $^{25-27}$. Su discípulo y sucesor directo en dicha Cátedra Ordinaria o Titular fue el Dr. Enrique Onetto Aguilar (1928-1931) y luego el Dr. Hugo Vaccaro Kosovich (1931-1970). Paralelamente, se creó una segunda Cátedra denominada Cátedra Extraordinaria de Bacteriología e Inmunología, dirigida inicialmente por su discípulo Dr. Eugenio Suárez Herreros (1929-1950) y luego por el Dr. Eduardo Dussert Jolland (1950-1973). La Cátedra Extraordinaria funcionó siempre en dependencias del Instituto Bacteriológico de Chile.

Esta breve reseña histórica sobre los orígenes de la Bacteriología Experimental en Chile, demuestra que a fines del siglo XIX, durante la época de oro de la Bacteriología, en los Laboratorios de Histología y Anatomía Patológica de la Universidad de Chile, ya se cultivaba esta ciencia y se publicaban trabajos bacteriológicos originales con las herramientas más modernas de la época.

\section{Referencias}

1. Leyes y Decretos. Programa de los cursos de la instrucción universitaria para el año 1852. AUCH 1852; 9: 274.

2. Cruz-Coke R. Historia de la Medicina Chilena. Editorial Andrés Bello, Primera Edición, Santiago de Chile, 1995.

3. Orrego Luco A. Recuerdos de la Escuela. Editorial Francisco de Aguirre S.A., Buenos Aires, Argentina, 1976.

4. Ferrer PL. Historia General de la Medicina en Chile. Talca, Chile, 1904.

5. Sierra L. Cien años de la enseñanza de la medicina en Chile. An Fac Biol Méd 1934; 1: 1-134.

6. Wormald R. Memoria presentada a la Facultad de Medicina para obtener el grado de Licenciado. AUCH 1852; 9: 405-15.

7. Tocornal FJ. Sobre el origen miasmático de las fiebres intermitentes analizando el tratado que sobre esta materia ha publicado el Dr. Félix Jacquot. AUCH 1857; 15: 476-9.

8. Saldías V. Causa de las epidemias. AUCH 1865; 26: 35173.

9. Allende Padin R. Observaciones sobre el tifo, conocido en Chile vulgarmente con el nombre de Chavalongo. AUCH 1865; 26: 503-25.

10. Zorrilla P. Consideraciones sobre la fiebre puerperal. AUCH 1862; 20: 174-87.

11. Murillo A. Apuntes para servir a la historia de las enfermedades del hígado en Chile: -terminación de los 
abscesos hepáticos. AUCH 1862; 20: 73-127.

12. Candia P. Jeneración espontánea. Rev Med Chile 1874; 1: 105-13.

13. Costa-Casaretto C. Los primeros becarios chilenos en Europa (1874); Rev Med Chile 107: 432-7.

14. Izquierdo V. El Bacillus Kochii i la tuberculosis. Rev Med Chile 1883; 12: 39-49.

15. Izquierdo V. El microbio de la blenorrajia. Rev Med Chile 1884; 13: 16-21.

16. Campos Menéndez E. Una vida por la vida. Vicente Izquierdo Sanfuentes. Un gran médico chileno y su época (1850-1926). Ediciones Universidad Católica de Chile, Santiago, Chile, 1995.

17. Núñez H, Osorio G. La arqueología del Hospital San Vicente de Paul. Rev Med Chile 2007; 135:264-269.

18. Del Río A. El micro-organismo de la disentería. Rev Med Chile 1888; 17: 267-9.

19. Del Río A. Contribución al estudio de la etiología y anatomía patológica de los abscesos del hígado. Rev Med
Chile 1889; 18: 249-305.

20. Puelma Tupper F. Apuntes para la historia de la medicina en Chile. Rev Med Chile 1919; 47: 882-6.

21. Oyarzún A. Homenaje al Dr. Francisco Puelma Tupper. AUCH 1939; 33: 10-25.

22. Oyarzún A. Informe del doctor Oyarzún Navarro sobre contribución al estudio de la anatomía patolójica del cólera asiático. Rev Med Chile 1887; 15: 361-85.

23. Prado Tagle E. El Dr. Aureliano Oyarzún. AUCH 1939; 33: 5-9.

24. Couchot JM. Dr. Alejandro del Río. Rev Med Chile 1971; 99: 892-6.

25. González Ginouves I. El Dr. Mamerto Cádiz. Rev Med Chile 1983; 111:1307-10.

26. Laval E. Noticias sobre los médicos en Chile. Editorial Historia Médica, Santiago, Chile, 1972.

27. Rodríguez M. La microbiología en Chile: su desarrollo a la luz de un siglo de existencia. Rev Med Chile 1992; 120: 463-70. 